\title{
The investigation of load-bearing capacity of soil base for oil pipeline depending on local geocryological conditions
}

\author{
Sergei Kudriavtcev ${ }^{1,}{ }^{*}$ and Viacheslav Kovshun ${ }^{1}$ \\ ${ }^{1}$ Far Eastern State Transport University, 47 Seryshev St., Khabarovsk, 680021, Russia
}

\begin{abstract}
Weak thawing soils around the metal piles pose the main danger when constructing oil pipelines or other engineering structures located in the cryolithozone. The occurrence of ice inside soil causes thermokarst dips and settlement while thawing. High-precision calculations of the loadbearing capacity of soils and accurate forecasts of the amount of thawing in summer are necessary for improving the reliability of engineering structures. Thermopiles are used to prevent thawing of soils around piles and thermally stabilize the permafrost condition. In this article, one of such decisions is considered on the example of oil pipeline along «Kuyumba Taishet - Kozmino» route in Russia. There are permafrost and deformations of the soil body in the base of oil pipeline. The proposed method implies the joint operation of holding soils in frozen state with help of seasoncooling devices or thermopiles. It was concluded that special geotechnical engineering for permafrost projects is necessary to avoid the main problems. In order to achieve the goals of the present investigation, the geotechnical software complex «FEM-models» with «Termoground» was used.
\end{abstract}

\section{Introduction}

Permafrost occupies $65 \%$ of the territory of Russia. Development of effective construction methods in specific conditions of these areas is very important. It is necessary to provide protective measures for preventing buckling of foundations during period of freezing of ground. The unfavorable climatic conditions of the northern regions create many problems for building engineering objects. There are a lot of ices in frozen soils. The ice inside the soil is melt and structure experiences settlement and structural damage depend on the spatial arrangement and configurations of ice inclusions.

Thermopiles or season-cooling devices are used as foundation of oil pipeline or other engineering structures. Season-cooling devices are designed to keep soils in frozen state and ensure the stability of structures on piles.

\footnotetext{
*Corresponding author:prn@festu.khv.ru
} 
Thermopiles are widely used for thermostabilization of the permafrost. Thermopile contains encapsulated tubular immersion liquid or vapor-liquid devices, which are used for creating frozen state around the pile. Season-cooling devices are charged with a working fluid circulating between an evaporator and a condenser or a radiator due to the natural convection. The ammonia or carbon dioxide are used as refrigerant, which are transferred through the system without any resources.

As a result, heat from ground is transferred to a condenser. Ammonia refrigerant was the most popular substance of thermostabilizing systems, but it has been classified as an IV class of danger by the degree of toxicity. In this way, using of thermostabilization systems was possible only in the industrial buildings and structures. Scientists and engineers of the NPO «Fundamentstroyarcos» adapted carbon dioxide for thermostabilization systems in 2013.

Carbon dioxide is a refrigerant, which is absolutely safe. Thermopiles do not need an external power source, what is important feature for our nature. In winter, the ground temperature is higher than the air temperature, so the fluid at the base of the season-cooling device warms up, vaporises and moves upward to the radiator where the liquid cools down by colder air, condenses and moves downward again. This loop transfers heat from the ground to the air as long as the appropriate temperature difference prevails, otherwise, the system stops working. Therefore, the cycle ceases in summer with partial thawing of the active layer of soil.

Analytical investigation of freezing and thawing processes of oil pipeline ground should carry out with help of numerical modeling in the annual freeze-thaw cycle by the finite element method.

\section{Calculation of the load bearing capacity of the oil pipeline base}

Calculation of the load bearing capacity of the oil pipeline base has been made with help of SR 25.13330.2012 "Soil bases and foundations on permafrost soils" of the Russian Federation.

\subsection{Methods of calculation}

The main condition of calculation of oil pipeline base by first group of limit states is following:

$$
\mathrm{F} \leq \mathrm{F}_{\mathrm{u}} / \gamma_{\mathrm{n}}
$$

where $\mathrm{F}$ - calculated load on the base; $\mathrm{F}_{\mathrm{u}}$ - load bearing capacity of the base, determined by calculation, $\gamma_{n}$ - coefficient of reliability on responsibility of construction.

Calculation of the load bearing capacity of oil pipeline base was carried out using the formula:

$$
F u=\gamma_{\mathrm{t}} \cdot \gamma_{\mathrm{c}} \cdot\left(\mathrm{RA}+\sum_{i=1}^{n} \mathrm{R}_{\mathrm{af}, \mathrm{i}} \cdot \mathrm{A}_{\mathrm{af}, \mathrm{i}}\right)
$$

where $\gamma_{t}$ - temperature coefficient, taking changes in the temperature of the ground base due to random changes in the temperature of the outside air; $\gamma_{c}$ - coefficient of conditions of ground work; R - calculated resistance of frozen soil under the lower end of the pile, $\mathrm{kPa}$; A - the area of pile support on the ground, $\mathrm{m}^{2} ; \mathrm{R}_{\mathrm{af}, \mathrm{i}}$ - calculated resistance of frozen soil or ground solution to shear along the lateral surface of pile frost, $\mathrm{kPa} ; \mathrm{A}_{\mathrm{af}, \mathrm{i}}$ - surface area of the freezing surface of the $\mathrm{i}$-th layer of soil with the side surface of the pile. 


\subsection{Initial data}

Calculation of the necessary load-bearing capacity of base carried out along the route of «Kuyumba-Taishet-Kozmino» pipeline. Initial data which used for calculation is following: steel pipe 3 - 1020x20 GOST R 52079-2003 of the Russian Federation, oil density is $850 \mathrm{~kg}$ $/ \mathrm{m} 3$, metal thermopiles $500 \mathrm{~mm}$ in diameter and $5 \mathrm{~m}$ in length used as foundation (Fig. 1,2). The values of coefficients and soil strength were taken according to the tables of SR 25.13330.2012 " Soil bases and foundations on permafrost soils " of the Russian Federation.

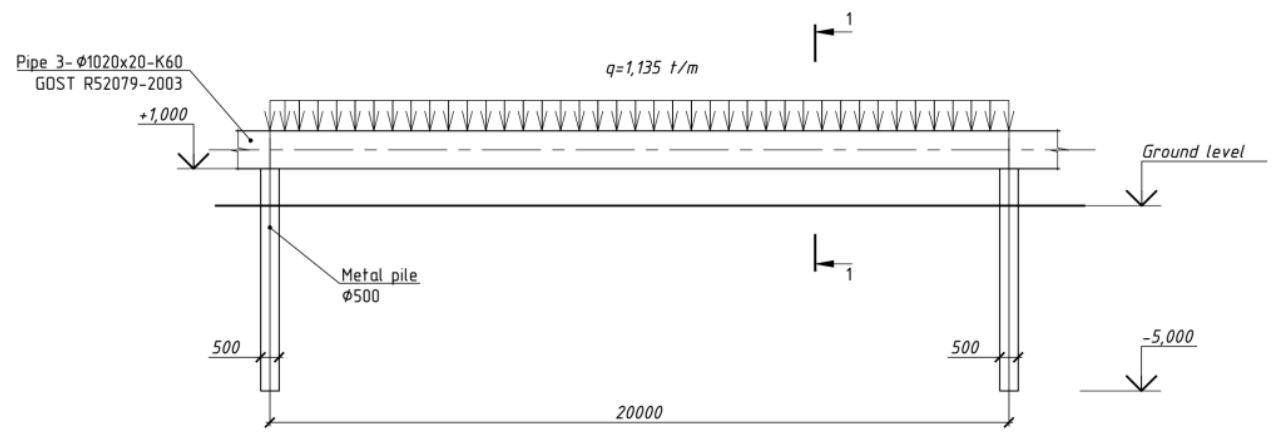

Fig. 1. Initial design scheme of pipeline

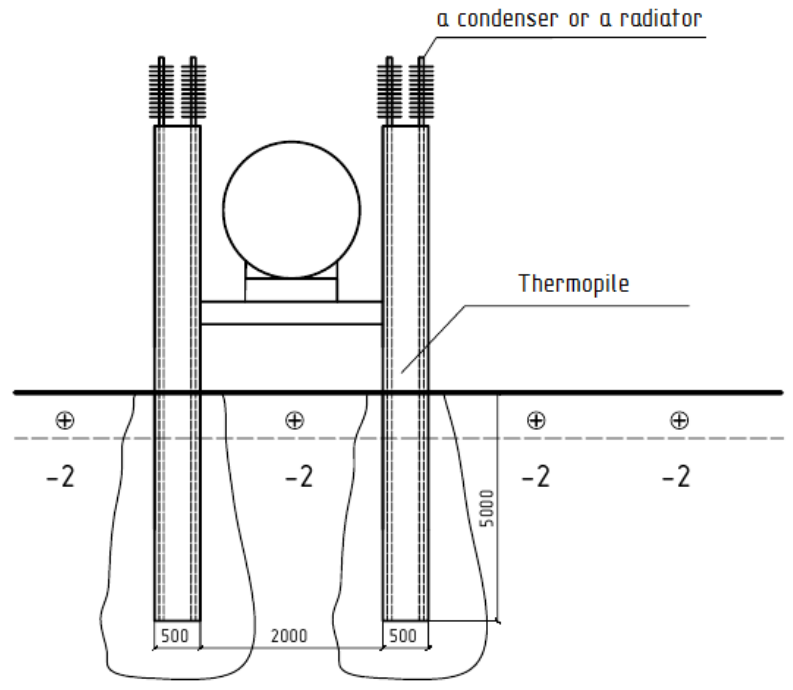

Fig. 2. Section 1-1.

The greatest value of the load on the thermopile is 13.62 tons.

The methods of numerical simulation have been applied to analyse the processes of freezing and thawing of the soil with thermopiles base. Geotechnical software complex FEMmodels is able to simulate the work of the facilities in its stress-strain state, the thermodynamic processes in the annual freeze-thaw cycle and evaluation stability of soil bodies and structures. «FEM models» is designed by the geotechnical engineers of St. Petersburg under the direction of Professor V.M. Ulitsky. «Termoground» is integral part of «FEM-models» software, which allows you to calculate values of freezing and thawing in the spatial model with help of numerical simulation in the annual cycle and the finite element method.

General equation describing the freezing and thawing processes for a transient thermal regime in a three dimensional soil space can be expressed as following: 


$$
C_{t h(f)} \rho \frac{\partial T}{\partial t}=\lambda_{t h(f)}\left(\frac{\partial^{2} T}{\partial x^{2}}+\frac{\partial^{2} T}{\partial y^{2}}+\frac{\partial^{2} T}{\partial z^{2}}\right)+q_{V}
$$

where $C_{t h(f)}$ - specific heat of soils (frozen or thawed), J/kgK; $\rho$ - soil consistency, $\mathrm{kg} / \mathrm{m}^{3}$; $\mathrm{T}$ - temperature, $\mathrm{K} ; \mathrm{t}$ - time, $\mathrm{c} ; \lambda_{\operatorname{th}(f)}$ - thermal conductivity of soil (frozen and thawed), $\mathrm{W} / \mathrm{mK} ; \mathrm{x}, \mathrm{y}, \mathrm{z}$ - coordinates, $\mathrm{m}$; qv- internal heat source capacity, $\mathrm{W} / \mathrm{m}^{3}$.

The core of a mathematical modeling of thermophysical processes in "Termoground" program is the model of high ice, thawed and frozen soils offered by N.A. Tsytovich, Y.A. Kronik and V.F. Kiselev.

The major factors determining the defined surface temperatures on the embankment elements and the adjacent territory are the atmospheric air temperature and the heat exchange conditions between the air and the structure surface that depend on the wind conditions, solar radiation, vaporation, and others.

The calculation value of the defined average monthly air temperature is determined from the formula:

$$
T_{c}=T_{\alpha}+\Delta t_{r}-\Delta t_{e}
$$

where $T_{\alpha}$ is average monthly air temperature, ${ }^{\circ} \mathrm{C} ; \Delta t_{r}$ and $\Delta t_{e}$ are corrections to average monthly air temperatures due to solar radiation and evaporation, ${ }^{\circ} \mathrm{C}$.

The correction to air temperature due to solar radiation $(\Delta t)$ is calculated according to formula:

$$
\mathrm{t}_{\mathrm{r}}=\frac{R}{0.073 \alpha}
$$

where $\mathrm{R}$ is monthly sum of radiation balance for the considered element of the surface, $\mathrm{kkal} / \mathrm{cm}^{2} \cdot$ months; $\alpha$ is surface heat exchange coefficient, $\mathrm{kkal} / \mathrm{m}^{2} \cdot \mathrm{h} \cdot{ }^{\circ} \mathrm{C}$, and its empiricalformula dependence is:

$$
\alpha=10 \sqrt{V}
$$

where $\mathrm{V}$ is wind velocity.

The monthly sums of radiation balance for horizontal surfaces are determined from the formula:

$$
R_{o}=Q_{o} \times k-0.42
$$

where $\mathrm{Q}_{0}$ is average monthly sum of total solar radiation striking the horizontal surface, $\mathrm{kkal} / \mathrm{cm}^{2} \cdot \mathrm{months} ; \mathrm{k}-$ empirical coefficient in terms of the surface reflecting capacity (albedo).

The monthly sums of radiation balance for bevel faces (subgrade embankments) are determined from the formula:

$$
R_{\beta}=\left(m_{\beta} I_{o}+P_{\beta} D_{o}\right) \times k-0.42
$$

where Io and $\mathrm{D}_{\mathrm{o}}$ - average monthly sums of direct and diffuse radiations striking the horizontal surface, $\mathrm{kkal} / \mathrm{cm}^{2} \cdot$ months, the values being taken from the climatological guide; $\mathrm{mb}$ - nondimensional coefficient in terms of the bevel face angle to horizon and spatiolization of the face for beam radiation intake. 
$\mathrm{Pb}-$ coefficient in terms of the bevel face angle to the horizon and spatialization of the face for a sky radiation intake that is determined from the formula:

$$
P_{\beta}=\cos ^{2} \frac{\beta}{2}
$$

where $b$ - angle of the bevel face to the horizon, degrees.

The thermophysiscal characteristics of the roadway and roadbed soils in thawed and frozen states are taken in accordance with the SR 25.13330.2012 - Permafrost Foundation Engineering Standards of the Russian Federation.

The relative thawing strains of permafrost are determined according to the results of the standard laboratory tests. In this case the relative stresses are calculated according to the formula:

$$
\varepsilon_{t h}=A_{t h}+\delta_{i t h}
$$

where $A_{t h}$ is the relative strain of thaw thermal subsidence; $\delta_{i t h}$ is the relative strain of thaw loading subsidence.

$$
\delta_{i t h}=m_{0 t h} \cdot p_{i}
$$

where $m_{0 t h}$ is the coefficient of compressibility of thaw soil (MPa-1); $p_{i}$ is the compacting vertical stress $(\mathrm{MPa})$.

\subsection{Calculation results}

The load-bearing capacity at different locations and temperatures were obtained (Fig. 3). Graph shows load-bearing capacity - temperature dependence of ground in the annual period on average depth of basement in the permafrost conditions along the oil pipeline «KuyumbaTaishet-Kozmino» in Russia. It is observed that ground temperature variation influences value of the load-bearing capacity. It is also observed that the lower temperatures are, the larger value of the load-bearing capacity is.

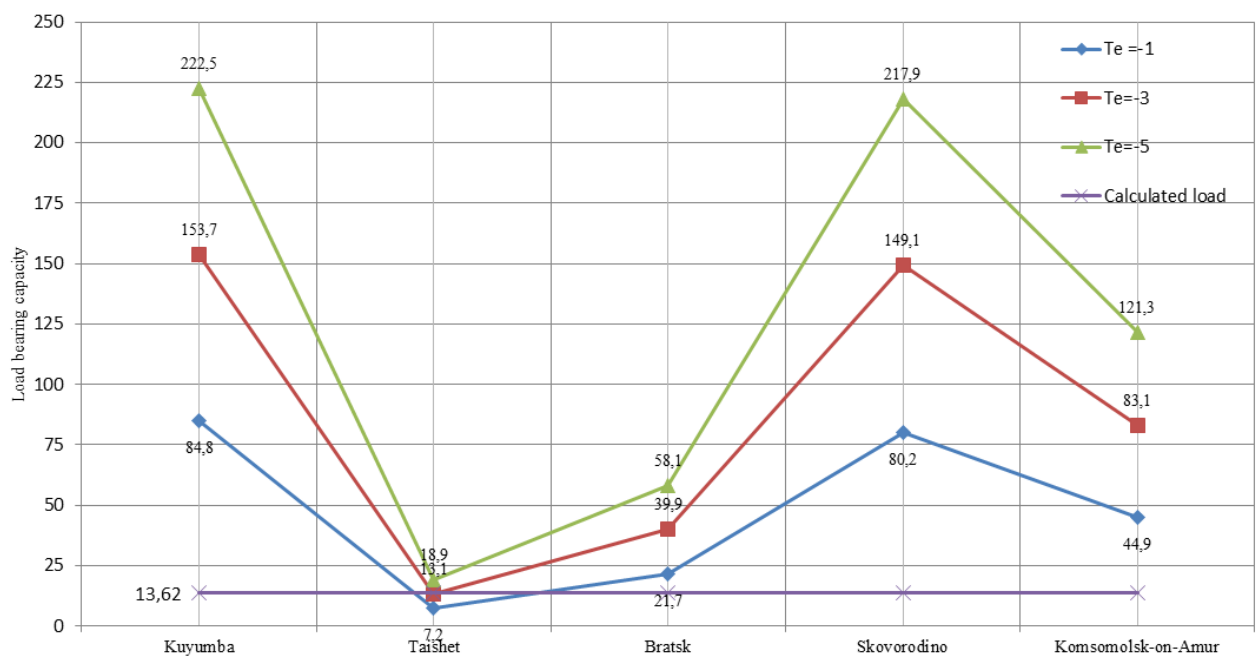

Fig. 3. Evolution of the load-bearing capacity at different locations and temperatures with compare of load on the thermopile. 
Note that the thermodynamic calculation does not consider heating effect of infiltration of precipitation into the soil and transverse filtration of groundwater, because of absence of monitoring data. Therefore, forecasted temperature fields different from original data to the side of lower temperatures. This fact must be considered for cooling and anti-deformation measures.

Figure 4 shows results of thermodynamic calculations without season-cooling devices in the annual freeze-thaw cycle in July.

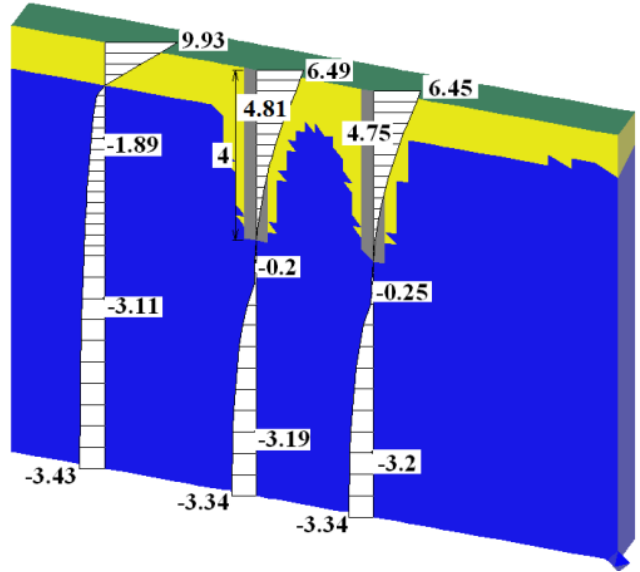

Fig. 4. Temperature field $\left(\right.$ in ${ }^{\circ} \mathrm{C}$ ) with thaw depth in July without season-cooling devices.

The maximum thaw depth of frozen ground around metal piles is $4.75 \mathrm{~m}$.

Figure 5 shows results of thermodynamic calculations with season-cooling devices in the annual freeze-thaw cycle in July.

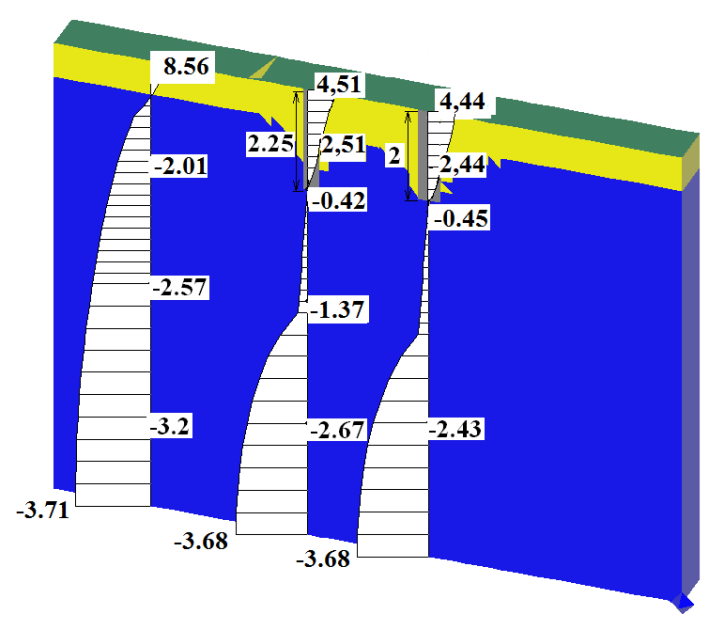

Fig. 5. Temperature field $\left(\right.$ in $\left.{ }^{\circ} \mathrm{C}\right)$ with thaw depth in July with season-cooling devices.

The maximum thaw depth of frozen ground around metal piles is $2.25 \mathrm{~m}$.

The performed analysis of the proposed solution showed high efficiency. The ground becomes much colder and thaw depth can be reduced by $50 \%$ compared with basement without season-cooling devices. A large region of the ground is maintained in a frozen state (Fig. 5) despite first calculation (Fig. 4). This illustrates the permafrost protection by seasoncooling devices that helps to stabilize the ground. 


\section{Conclusions}

1. According to the results of the numerical modeling the oil pipeline structure ought to construct above ground to prevent deformations and buckling of basement and to save permafrost in his original condition with help of seasonally-cooling devices or thermopiles.

2. The load-bearing capacity at different locations and temperatures was obtained with help of numerical simulation and SR 25.13330.2012 of the Russian Federation. The loadbearing capacity will increase if temperature of ground decreases.

3. The investigation showed that the ground becomes much colder and thaw depth was reduced by $50 \%$ compared with basement without season-cooling devices. The obtained results are consistent with physically-expected ground responses, showing the permafrost protection by season-cooling devices.

4. The performed analysis of the proposed solution showed increasing of load-bearing capacity with lowering of soil temperature. Using of thermopiles showed high efficiency and operational reliability of engineering structures.

\section{References}

1. S.A. Kudriavtcev, D.V. Grigoriev, Y.B. Berestyanyy, The 5th International Geotechnical Symposium-Incheon, Geotechnical engineering for disaster preventional \& reduction, 99-102 (2013)

2. V. Ulitsky, V. Paramonov, S. Kudryavtsev, A. Shashkin, K. Shashkin, Frost Heave Soil, 2nd Canadian Specialty Conference on Computer Applications in Geotechnique, 167171 (2002)

3. V. Ulitsky, V. Paramonov, S. Kudryavtsev, K. Shashkin, M. Lisyuk, Contemporary geotechnologies providing safe operation of railway embankments in permafrost conditions, 8th International Conference on Permafrost. Extended Abstracts, 167-168 (2003)

4. S.A. Kudryavtsev, Y. Berestyanyy, E. Goncharova, Engineering and Construction of Geotechnical Structures with Geotechnical Materials in Coastal Arctic Zone of Russia, The 23rd International Offshore (Ocean) and Polar Engineering Conference, 562-566 (2013) 